\title{
Comparing the effects of oxazepam and diazepam in actual highway driving and neurocognitive test performance: a validation study
}

\author{
S. Jongen ${ }^{1}$ (D) E. F. P. M. Vuurman ${ }^{1}$ - J. G. Ramaekers ${ }^{1}$ - A. Vermeeren ${ }^{1}$
}

Received: 8 January 2018 / Accepted: 28 January 2018 / Published online: 2 March 2018

(C) The Author(s) 2018. This article is an open access publication

\begin{abstract}
Objective Screening of drug-induced performance impairment is needed to provide meaningful information for users and prescribers regarding the impact of drugs on driving. The main objective was to assess the effects of oxazepam $10 \mathrm{mg}$ (OXA10), oxazepam $30 \mathrm{mg}$ (OXA30), and diazepam $10 \mathrm{mg}$ (DIA10) on standard deviation of lateral position (SDLP) in a highway driving test in actual traffic and to determine the ability of eight neurocognitive tests to detect comparable effects.

Methods Twenty-three healthy volunteers participated in a four-way double-blind, placebo-controlled, crossover study. The highway driving test was conducted between 4 and $5 \mathrm{~h}$ after drug intake. A range of neurocognitive tests was conducted before and after driving, 2 and $6 \mathrm{~h}$ post-treatment, respectively.

Results Mean SDLP increased by 1.83,3.03, and $7.57 \mathrm{~cm}$ after OXA10, DIA10, and OXA30, respectively. At $2 \mathrm{~h}$ post-treatment, all neurocognitive tests, except the useful field of view, showed performance impairment in all active treatments. Effect sizes (ES) were moderate for OXA10, large ES for DIA10, and largest ES for OXA30. Modest correlations were found between changes in SDLP and performance in the attention network test (ANT), the divided attention test (DAT), and the psychomotor vigilance test (PVT).

Conclusion OXA10 caused minor, DIA10 moderate, and OXA30 severe driving impairment. No neurocognitive test was both dose dependently sensitive and able to be associated with driving impairment. No neurocognitive test can replace the on-the-road highway driving test.
\end{abstract}

Keywords Oxazepam $\cdot$ Diazepam $\cdot$ Neurocognitive tests $\cdot$ SDLP $\cdot$ On-the-road highway driving test $\cdot$ Attention

\section{Introduction}

Psychoactive drugs can have side effects, such as sedation and reduced alertness, which can cause driving impairment and increase crash risk (Dassanayake, Michie, Carter, and Jones,

S. Jongen

stefan.jongen@maastrichtuniversity.nl

E. F. P. M. Vuurman

eric.vuurman@maastrichtuniversity.nl

J. G. Ramaekers

j.ramaekers@maastrichtuniversity.nl

A. Vermeeren

a.vermeeren@maastrichtuniversity.nl

1 Neuropsychology and Psychopharmacology section, Faculty of Psychology and Neuroscience, Maastricht University, Maastricht, The Netherlands
2011; O'Hanlon, Haak, Blaauw, and Riemersma, 1982; Seppala, Linnoila, and Mattila, 1979). Screening a drug's potential to impair the ability to operate a motor vehicle is a necessary means to provide meaningful precautions for users and prescribers of medicinal drugs (Food Drug Administration, 2015; Kay and Logan, 2011; O'Hanlon, 1986).

Ideally, drug evaluations should follow a tiered approach starting with neurocognitive tests, followed by driving simulators and finally on-the-road tests, as the latter generally have better validity to assess driving impairment (Berghaus and Friedel, 1999; Alvarez and del Río, 2002; Vermeeren, De Gier, and O'Hanlon, 1993; Walsh, Verstraete, Huestis, and Mørland, 2008). The standardized on-the-road highway driving test used in the Netherlands (O'Hanlon, 1984; Ramaekers, 2003; Vermeeren, 2004; Verster and Roth, 2011) is a sensitive and reliable test to assess drug-induced driving impairment. Standard deviation of lateral position (SDLP), the primary outcome measure, has been shown to be sensitive to the 
effects of many sedative drugs (Leufkens and Vermeeren, 2014; O'Hanlon and Ramaekers, 1995; Ramaekers, 2003; Roth, Eklov, Drake, and Verster, 2014). In addition, SDLP has high validity to predict crash risk, as alcohol-induced changes in SDLP are highly correlated $(r=0.99)$ with alcohol-induced changes in crash risk (Borkenstein et al., 1964; Owens and Ramaekers, 2009).

Initial screening of a drug's impairing potential can be conducted with neurocognitive tests as these are generally easy to administer and cost-effective. However, such neurocognitive tests should be validated for drug sensitivity and generalizability to actual driving in order to provide reliable outcome measures (ICADTS, 1999; Vermeeren, De Gier and O'Hanlon, 1993; Walsh, Verstraete, Huestis, and Mørland, 2008). A number of neurocognitive tests have been calibrated by several doses of alcohol reaching blood alcohol concentrations (BAC) of 0.2, 0.5, and $0.8 \mathrm{~g} / \mathrm{L}$ (Jongen, Vuurman, Ramaekers, and Vermeeren, 2014). Results suggested that of the selected tests, the psychomotor vigilance test (PVT) and the divided attention test (DAT) are most promising as initial screening tests to detect drug-induced impairment. A follow-up study found that the PVT, DAT, and attention network test (ANT) were most sensitive to the effects of one night of sleep deprivation and showed moderate associations with driving impairment as measured with changes in SDLP (Jongen, Perrier, Vuurman, Ramaekers, and Vermeeren, 2015).

However, sensitive neurocognitive tests to the effects of alcohol or sleep deprivation are not necessarily able to detect impairing effects of medicinal drugs. For example, the impairment profiles of alcohol and benzodiazepines have been found to differ (Kleykamp, Griffiths, and Mintzer, 2010; Tiplady, Hiroz, Holmes, and Drummond, 2003). The neurocognitive tests selected for the present study were the psychomotor vigilance test (PVT), critical tracking test (CTT), divided attention test (DAT), attention network test (ANT), digit symbol substitution test (DSST), useful field of view test (UFOV), postural balance test (PBT), and the determination test (DT), because these were previously found to be sensitive to the effects of alcohol or sleep deprivation (Jongen et al. 2014, 2015).

The aim of the present study was to assess the sensitivity of a selection of neurocognitive tests to the effects of two medicinal drugs known to impair driving performance, i.e., the benzodiazepines diazepam and oxazepam (Neutel, 1995; Ray, Fought, and Decker, 1992). These medicinal drugs were selected because diazepam $10 \mathrm{mg}$ has been recommended as verum for experimental studies assessing the effects of medicinal drugs on driving (Berghaus et al. 1999). Oxazepam is currently the most frequently prescribed benzodiazepine in many countries (in recommended doses of 10 to $30 \mathrm{mg}$ per day). Recent epidemiological studies have shown that both diazepam and oxazepam are highly prevalent in impaired drivers (e.g., Bezemer et al. 2014).
Thus, the primary objective of the present study was to validate the sensitivity of a range of neurocognitive tests mentioned above to the effects of oxazepam $(10$ and $30 \mathrm{mg})$ and diazepam $10 \mathrm{mg}$ and compare it with driving impairment (i.e., SDLP changes in the highway driving test). Secondary aims were to establish mean performance changes in each neurocognitive test associated with each drug and dose for future reference and to determine correlations between druginduced performance changes in neurocognitive tests and onthe-road highway driving.

\section{Methods}

\section{Participants}

Twenty-three healthy volunteers (12 males, 11 females) aged between 21 and 50 years were recruited through advertisements in local papers and at the University of Maastricht. Initial screening was based on a medical history questionnaire examined by the medical supervisor. Eligible participants were invited for a physical examination, which included urinalysis, tests for drugs of abuse (amphetamines, benzodiazepines, cannabis, cocaine, 3,4methylenedioxymethamphetamine, and opiates), and a 12lead electrocardiogram. The following inclusion criteria had to be met: possession of a valid driving license for 3 years or more, driving experience of at least $5000 \mathrm{~km}$ per year on average over the last 3 years, and a body mass index (BMI) between 19 and $29 \mathrm{~kg} \mathrm{~m}^{-2}$. Exclusion criteria included the following: shift work; history of a sleep disorder; extreme morning or evening type as measured with the Morning Evening Questionnaire (MEQ; Horne and Ostberg, 1976); any history of psychiatric or medical illness; history or current drug or alcohol abuse; current use of psycho-active medication; excessive caffeine use, defined as drinking six or more cups of coffee per day.

The mean $( \pm \mathrm{SD})$ age of the participants was $36.8( \pm 9.5)$ years. The study was conducted in accordance with the code of ethics on human experimentation established by the declaration of Helsinki (1964) and amended in Seoul (2008). All participants were informed about the study's goal, procedures, and potential hazards in writing, and they gave their informed consent in writing. The Medical Ethics Committees of Maastricht University approved the study. Participants received a financial compensation for their participation in the study.

\section{Design}

The study was conducted according to a 4-way, randomized, double-blind, placebo-controlled, crossover design. The four 
treatment conditions were single oral doses of oxazepam $10 \mathrm{mg}$ (OXA10), oxazepam $30 \mathrm{mg}$ (OXA30), diazepam $10 \mathrm{mg}$ (DIA10), and placebo (PBO). Order of treatment conditions was balanced over participants by using a William design. Washout periods between treatments were at least 7 days. To reduce order effects of neurocognitive tests, two neurocognitive test sequences were applied and these were balanced over participants.

\section{Procedure}

Participants were individually trained to perform the behavioral tests prior to the first treatment day. Participants agreed not to use any drugs of abuse or oral medication (except oral contraceptives and paracetamol) during the study. During participation in the study, alcohol intake was not allowed from $24 \mathrm{~h}$ prior to each test day until discharge. On treatment days, caffeine intake and smoking were not allowed until discharge.

On treatment days, participants arrived at the testing site at 8.45 or 10.00 h. The Groningen Sleep Quality Scale (MulderHajonides van der Meulen, 1981) was administered to assess sleep quality, and urine and breathe samples were yielded to assess compliance with use of drugs and alcohol. Four participants were tested on each testing day. Participants ingested a single treatment dose at 9:00 am, 9:05 am, 10:15 am, or 10:20 am. Four hours after drug intake, the standardized highway driving test was conducted. Before and after the driving test, i.e., 2 and $6 \mathrm{~h}$ after treatment intake, participants performed two sessions of laboratory testing (session 1 and session 2). Each session consisted of the PVT, CTT, DAT, ANT, DSST, UFOV, PBT, and DT. Before the driving test, a standardized light lunch was served. After completion of session 2 (at 4:00 pm or $5.15 \mathrm{pm}$ ), participants were transported home by study personnel. See Fig. 1 for a timeline of the study procedures.

\section{Assessment}

\section{Highway driving test}

In the standardized highway driving test (O'Hanlon, 1984; Verster and Roth, 2011), the participant operates a specially instrumented vehicle for approximately $1 \mathrm{~h}$ over a $100-\mathrm{km}$ (61-mile) primary highway circuit (A2 Netherlands, Maastricht-Weert v.v.), accompanied by a licensed driving instructor having access to dual controls. The task of the participant is to maintain a constant speed of $95 \mathrm{~km} / \mathrm{h}(58 \mathrm{~m} / \mathrm{h})$ and a steady lateral position between the delineated boundaries of the right traffic lane. The vehicle's speed and lateral position are recorded continuously. These signals are digitized at a rate of $4 \mathrm{~Hz}$ and edited off-line to remove data recorded during overtaking maneuvers or disturbances caused by roadway or traffic situations. The remaining data are then used to calculate mean values and standard deviation of lateral position and speed. The primary outcome variable is standard deviation of lateral position (SDLP, in $\mathrm{cm}$ ) which is a measure of road tracking error or 'weaving'.

\section{Psychomotor vigilance test}

The psychomotor vigilance test (PVT) is based on a simple reaction time test (Dinges and Powell, 1985). Dependent variables are mean reaction time (RT in $\mathrm{ms}$ ) and number of lapses (RT $>500 \mathrm{~ms}$ ). In addition, inverse reaction times (I/RT) were calculated, as it emphasizes slowing in the optimum and intermediate response domain and substantially decreases the contribution of long lapses (Basner and Dinges, 2011). Test duration is $10 \mathrm{~min}$.

\section{Critical tracking task}

The critical tracking task (CTT) measures the ability to control an unstable error signal using a joystick in a first-order compensatory tracking task (Jex, McDonnell, and Phatak, 1966). The frequency of cursor deviations at which the participant loses control is the critical frequency or lambda $\left(\lambda_{\mathrm{c}}\right.$ in $\left.\mathrm{rad} \mathrm{s}^{-} 1\right)$. Test duration is approximately $3 \mathrm{~min}$.

\section{Divided attention task}

The divided attention task (DAT) measures the ability to divide attention between two simultaneously performed tasks, a tracking task and a visual target detection task (Moskowitz, 1973). The primary dependent measures in the respective
Fig. 1 Timeline of a treatment day. Time points are relative to time of treatment administration

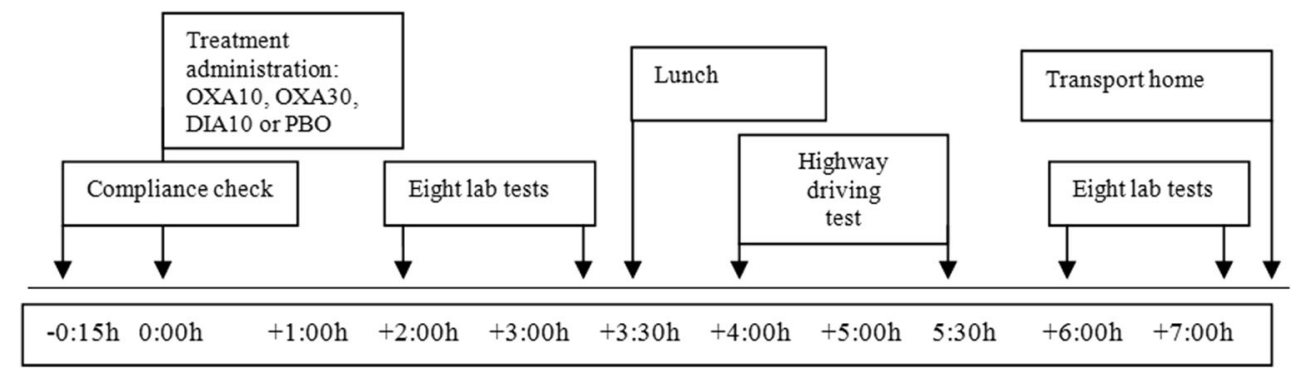


subtasks are tracking error (in $\mathrm{mm}$ ) and average reaction time to targets (in ms). Secondary control measures are number of control losses in the tracking task and number of hits in the target detection task. Task duration is $12 \mathrm{~min}$.

\section{Digit symbol substitution test}

The digit symbol substitution test (DSST) measures processing speed and working memory. A computerized version (McLeod, Griffiths, Bigelow, and Yingling, 1982) of the original paper-and-pencil test taken from the Wechsler Adults Intelligence Scale was used. The performance measure is the number of digits encoded correctly within $3 \mathrm{~min}$.

\section{Attention network test}

The attention network test (ANT) is a choice reaction time using different warning cues (no cue, double cue, center cue, spatial cue) and target stimuli (with congruent or incongruent flankers). It provides measures of three functions of attention, i.e., alerting, orienting, and executive attention (Fan, McCandliss, Sommer, Raz, and Posner, 2002). Dependent variables are total reaction time, alerting effect (i.e., RT no cue-RT double cue), orienting effect (RT center cue-RT spatial cue), and conflict effect (RT incongruent flankers-RT congruent flankers). The test duration is approximately $20 \mathrm{~min}$.

\section{Postural balance test}

The postural balance test (PBT) is measured by using the AMTI AccuSway System (Advanced Mechanical Technology, Inc., Watertown, MA) force platform. Postural sway is assessed by the area of the $95 \%$ confidence ellipse enclosing the center of pressure (A95 in $\mathrm{cm}^{2}$ ). The test is conducted with feet apart at hip's width in two trials of $60 \mathrm{~s}$ : one trial with the participants' eyes open and one trial with eyes closed.

\section{Determination test}

The determination test (DT) (Schuhfried, 2005) is a choice reaction time task measuring resilience of attention and reaction speed under conditions of sensory stress. The task is to identify various visual and auditory stimuli and to react to them by pressing the respective corresponding response buttons, using the response panel of the Vienna Test System. Median reaction time and correct responses were used to assess performance. Total duration of the test is $4 \mathrm{~min}$.

\section{Useful field of view test}

The test of useful field of view (UFOV) is a computerbased test measuring detection time for three subtests (visual processing speed, divided attention, and selective attention) which involve attentional tasks of increasing difficulty (Edwards et al., 2005). Total detection time was computed by summing the threshold scores for the three subtests. Total duration of the test is approximately $7 \mathrm{~min}$.

\section{Statistical analyses}

Sample size calculation was based on detecting a minimally relevant difference with an effect size of 0.25 in SDLP, the primary measure of this study. Given a testretest reliability of SDLP of at least $r=0.70$, a group of 22 participants should permit detection of a mean change of $2.0 \mathrm{~cm}$, with a power of at least $90 \%$ and an $\alpha$ of .05 . Using a Williams design to achieve balance in four treatment orders, a total of 24 participants were needed.

SDLP in the highway driving test was analyzed using general linear model (GLM) for repeated measures with treatment (OXA10, OXA30, DIA10, PBO) as withinsubject factor. Three paired sample $t$ tests were conducted to assess the drug-placebo contrasts. Each parameter of the neurocognitive tests was analyzed using a $Z \longleftarrow 4$ GLM repeated measures with treatment (OXA10, OXA30, DIA10, PBO) for sessions 1 and 2 separately. If a significant treatment effect was found, three paired sample $t$ tests were conducted between each treatment and placebo. If the model assumptions were violated, a suitable transformation was selected for analysis; if the assumption remained violated, a nonparametric method (i.e., Friedman test for a main effect and Wilcoxon signed-rank test for simple effects) was selected.

Change scores for each of the dependent variables were transformed to z-scores, which were calculated across the pooled changes in the active treatment conditions relative to placebo. This allows for easy comparison across each of the various performance tests (Dry, Burns, Nettelbeck, Farquharson, and White, 2012). In addition, to compare the magnitudes of the drug-placebo differences between tests and parameters, effect size (ES) statistics for repeated measure designs were calculated (i.e. $\mathrm{t}_{\mathrm{c}}[2(1-\mathrm{r}) / \mathrm{n}]^{1 / 2}$; Dunlap, Cortina, Vaslow, and Burke, 1996). Effect sizes between 0 and 0.19 are considered small, between 0.20 and 0.69 are considered moderate, and 0.70 or higher are considered large (Lakens, 2013).

Finally, Pearson's correlations were used to correlate change scores in session 1 and session 2 for each of the dependent variables with drug-placebo changes in SDLP. All statistical analyses were done by using the Statistical 
Package for the Social Sciences for Windows (version 21; SPSS Inc., Chicago, IL, USA).

\section{Results}

\section{Missing data}

One male participant did not participate in the OXA10 condition, due to reasons unrelated to the study drug. After DIA10, one female participant discontinued testing $3 \mathrm{~h}$ after drug intake, due to nausea. Consequently, no data were collected for this participant for the ANT in session 1, the driving test, and all neurocognitive tests in session 2 . Due to technical problems, no data of the balance test were available for one participant in the eyes open condition in session 2 after OXA10. The dataset of one male participant was removed from statistical analysis, because of non-compliance in the PBO condition. Extreme outliers, defined as values below the first or above the third quartile, were removed from the respective parameter. In the ANT, two outliers were identified, one in the orienting and one in the conflict effect. In the UFOV test, eight outliers were identified in seven participants. In the PBT, one outlier was identified in the eyes closed condition.

\section{Highway driving test}

Nineteen of 90 driving tests $(21.1 \%)$ were prematurely terminated. These driving tests were either terminated by the driving instructor as he judged the participant to be too drowsy to continue safely (i.e., in nine cases; two times after OXA10, two after DIA10, and five after OXA30) of by the participants when they felt to be too drowsy to continue safely (i.e., in ten cases: two times after OXA10, three after DIA10, and five after OXA30). In all of these cases, mean SDLP scores were calculated from the data collected up to the termination of the test.

Table 1 presents the mean (SE) of the mean SDLP scores. Analysis of variance showed a significant difference between treatments $\left(\mathrm{F}_{3,17}=19.67, p<0.001\right)$. Figure 2 shows the mean changes (i.e., $\triangle \mathrm{SDLP}$ ) from PBO compared to OXA10, DIA10, and OXA30. The mean SDLP score presented in Table 1 include all participants (i.e., $n=22, n=21, n=22$, $n=21$, for PBO, OXA10, OXA30, and DIA10, respectively). Because of missing data for one participant in the OXA10 and DIA10 condition, respectively, mean SDLP changes of OXA10 and DIA10 in Table 2 are calculated based on $n=$ 21 . Figure 2 shows mean SDLP changes of $+1.83,+3.03$, and $+7.57 \mathrm{~cm}$ for OXA10, DIA10, and OXA30, respectively, indicating $\triangle$ SDLP comparable to a BAC of $<0.5,0.5-0.8$, and $>0.8 \mathrm{~g} / \mathrm{L}$, respectively.

\section{Neurocognitive tests}

Table 1 presents a summary of the means and standard errors of the means (SE) of all performance scores and the results of the statistical analyses. In the PBT, A95 scores were not normally distributed and therefore log transformed (e.g., Boyle et al., 2009). After the log transformation, A95 scores were normally distributed. In the PVT, lapses were not normally distributed and therefore analyzed using non-parametric tests (i.e., Friedman test and Wilcoxon signed rank tests).

The DAT was terminated 23 times (12.7\%), as participants were unable to complete the test because of motor problems (> 50 control losses): four (OXA10), ten (OXA30), four (DIA10) times in session 1; three times (OXA30) and once (DIA10) in session 2. In addition, the test was once terminated in session 1 after PBO. Secondary control measures were first analyzed. A Friedman test was conducted, as control losses were not normally distributed. A Friedman test showed a statistically significant difference in control losses depending on treatment, $\chi^{2}(7)=25.03, p=0.001$. A combined score of control losses and tracking error was used to assess performance in the DAT. The distribution of control losses was highly skewed and transformations were applied to its logarithmic scores $(\log 10)$ before transformation to z-scores. $\log 10$ was applied to deal with zero values by using the formula NEWX $=$ LG10 $(X+1$.

Repeated measures analyses of variance showed a main effect of treatment in every parameter of the neurocognitive tests, except for orienting and alerting in the ANT. In session 1, all parameters showed impairment after OXA30 and DIA 10 compared to PBO, except for the UFOV after DIA10. In session 1 after OXA10, significant impairment was found in all tests, except the PVT, DAT, and UFOV.

In session 2 after OXA30, performance was still impaired in all tests except the CTT and UFOV; after DIA10, only the ANT and PBT with eyes open showed impairment. In session 2 after OXA10, no significant effect in any test was found.

\section{Effect sizes and correlations}

Table 2 shows a summary of mean treatment differences relative to PBO with 95\% confidence intervals, Dunlap's effect sizes, and significant correlations between changes of performance in the neurocognitive tests and $\triangle \mathrm{SDLP}$ in the highway driving test.

The ES of $\triangle$ SDLP in the highway driving test were moderate after OXA10 (0.47) to large after DIA10 and OXA30 (0.77 and 1.39 , respectively). In the neurocognitive tests, ES were generally moderate after OXA10, large after DIA10, and largest after OXA30. In addition, ES were larger in session 1 compared to session 2. Figure 3 shows transformed z-scores of change scores for each of the significant dependent variables across the pooled changes in the active treatment 


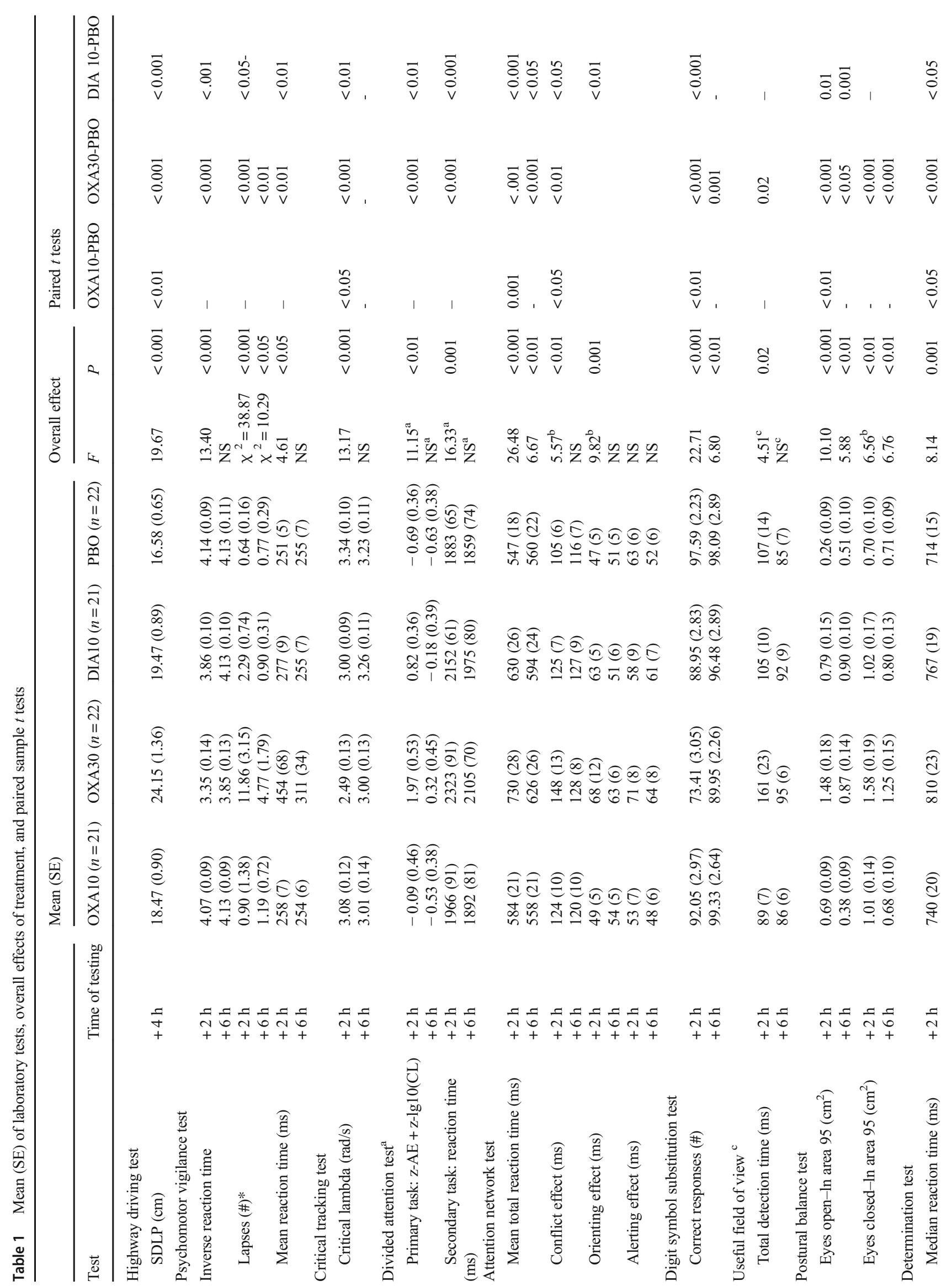



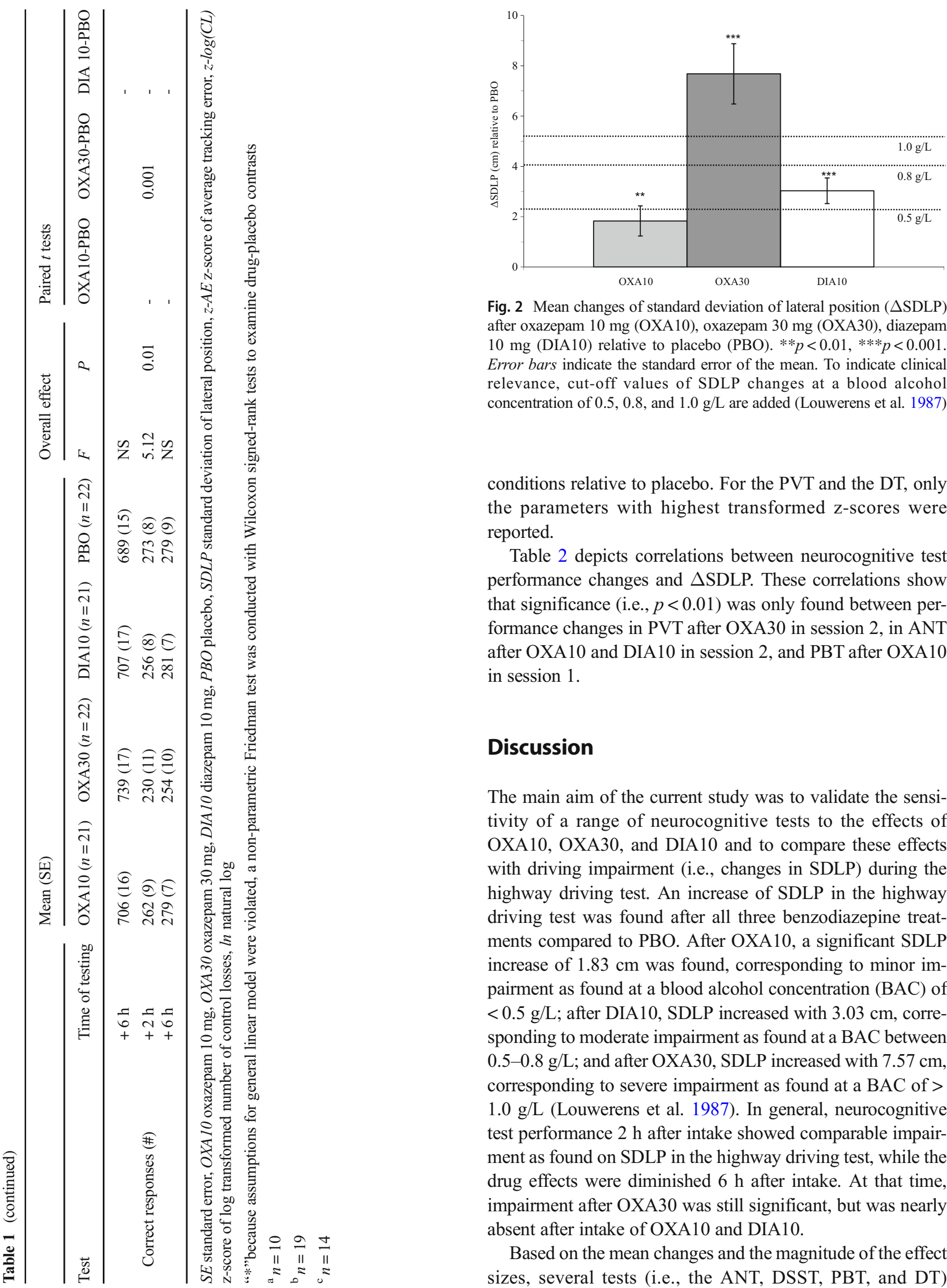

Fig. 2 Mean changes of standard deviation of lateral position ( $\triangle \mathrm{SDLP})$ after oxazepam $10 \mathrm{mg}$ (OXA10), oxazepam $30 \mathrm{mg}$ (OXA30), diazepam $10 \mathrm{mg}$ (DIA10) relative to placebo (PBO). $* * p<0.01, * * * p<0.001$. Error bars indicate the standard error of the mean. To indicate clinical relevance, cut-off values of SDLP changes at a blood alcohol concentration of $0.5,0.8$, and $1.0 \mathrm{~g} / \mathrm{L}$ are added (Louwerens et al. 1987)

conditions relative to placebo. For the PVT and the DT, only the parameters with highest transformed $\mathrm{z}$-scores were reported.

Table 2 depicts correlations between neurocognitive test performance changes and $\triangle$ SDLP. These correlations show that significance (i.e., $p<0.01$ ) was only found between performance changes in PVT after OXA30 in session 2, in ANT after OXA10 and DIA10 in session 2, and PBT after OXA10 in session 1 .

\section{Discussion}

The main aim of the current study was to validate the sensitivity of a range of neurocognitive tests to the effects of OXA10, OXA30, and DIA10 and to compare these effects with driving impairment (i.e., changes in SDLP) during the highway driving test. An increase of SDLP in the highway driving test was found after all three benzodiazepine treatments compared to PBO. After OXA10, a significant SDLP increase of $1.83 \mathrm{~cm}$ was found, corresponding to minor impairment as found at a blood alcohol concentration (BAC) of $<0.5 \mathrm{~g} / \mathrm{L}$; after DIA10, SDLP increased with $3.03 \mathrm{~cm}$, corresponding to moderate impairment as found at a BAC between 0.5-0.8 g/L; and after OXA30, SDLP increased with $7.57 \mathrm{~cm}$, corresponding to severe impairment as found at a BAC of $>$ $1.0 \mathrm{~g} / \mathrm{L}$ (Louwerens et al. 1987). In general, neurocognitive test performance $2 \mathrm{~h}$ after intake showed comparable impairment as found on SDLP in the highway driving test, while the drug effects were diminished $6 \mathrm{~h}$ after intake. At that time, impairment after OXA30 was still significant, but was nearly absent after intake of OXA10 and DIA10.

Based on the mean changes and the magnitude of the effect sizes, several tests (i.e., the ANT, DSST, PBT, and DT) 


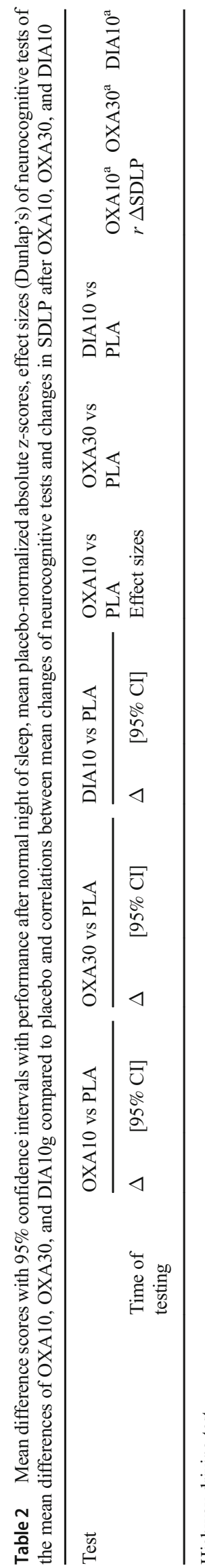

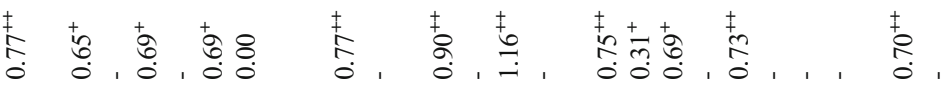
*

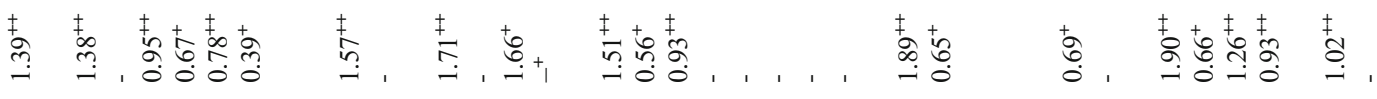

$\stackrel{+}{\stackrel{+}{+}}$

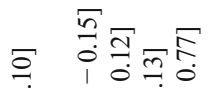

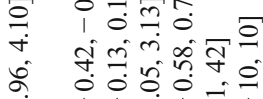

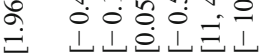

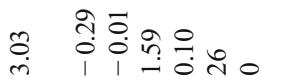

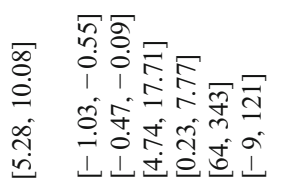

帛

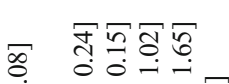

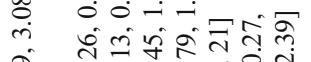

กิ กั०

ڤ +o

ㄱำ

ㅊํ इ

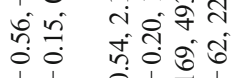

11

苛祭

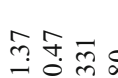

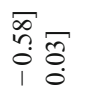

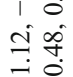

공ㅎํ

ㅊํㅇ

11

ڤึก

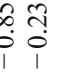

중휴 유ㅇㅠㅠ.

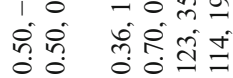

$\begin{array}{lll}1 & 1 & 1 \\ 0 & 0 & 0\end{array}$

กำ

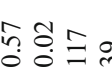

总, 势

草,

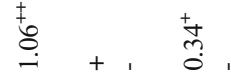

素素, 走。

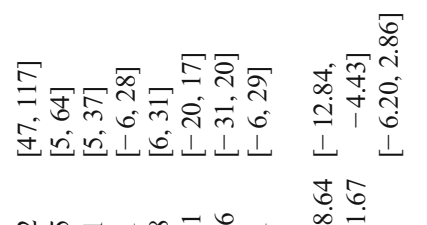

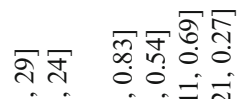

तै

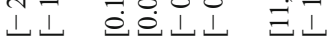

$n+\stackrel{+}{\overline{0}} \overline{0} \stackrel{\hat{0}}{0}$

芯士

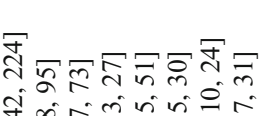

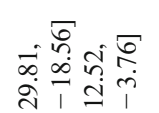

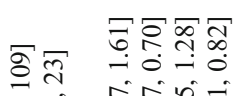

西

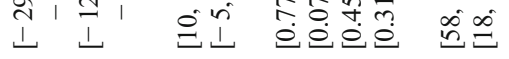

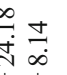

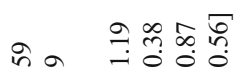

ㅅำ

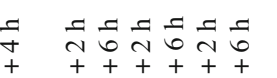

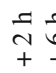

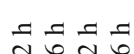

구의

공

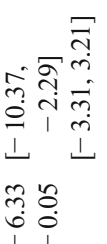

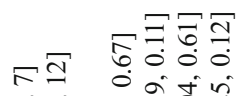

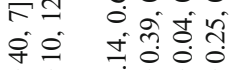

LI

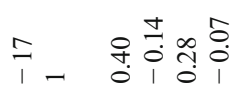

$\stackrel{\infty}{\infty} \stackrel{\infty}{-1}$
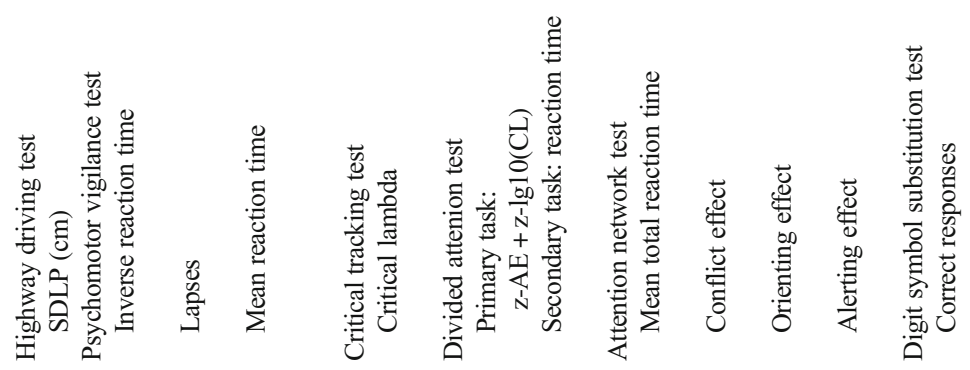

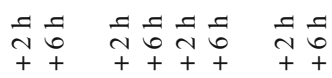

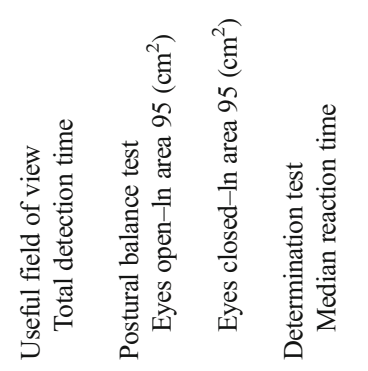




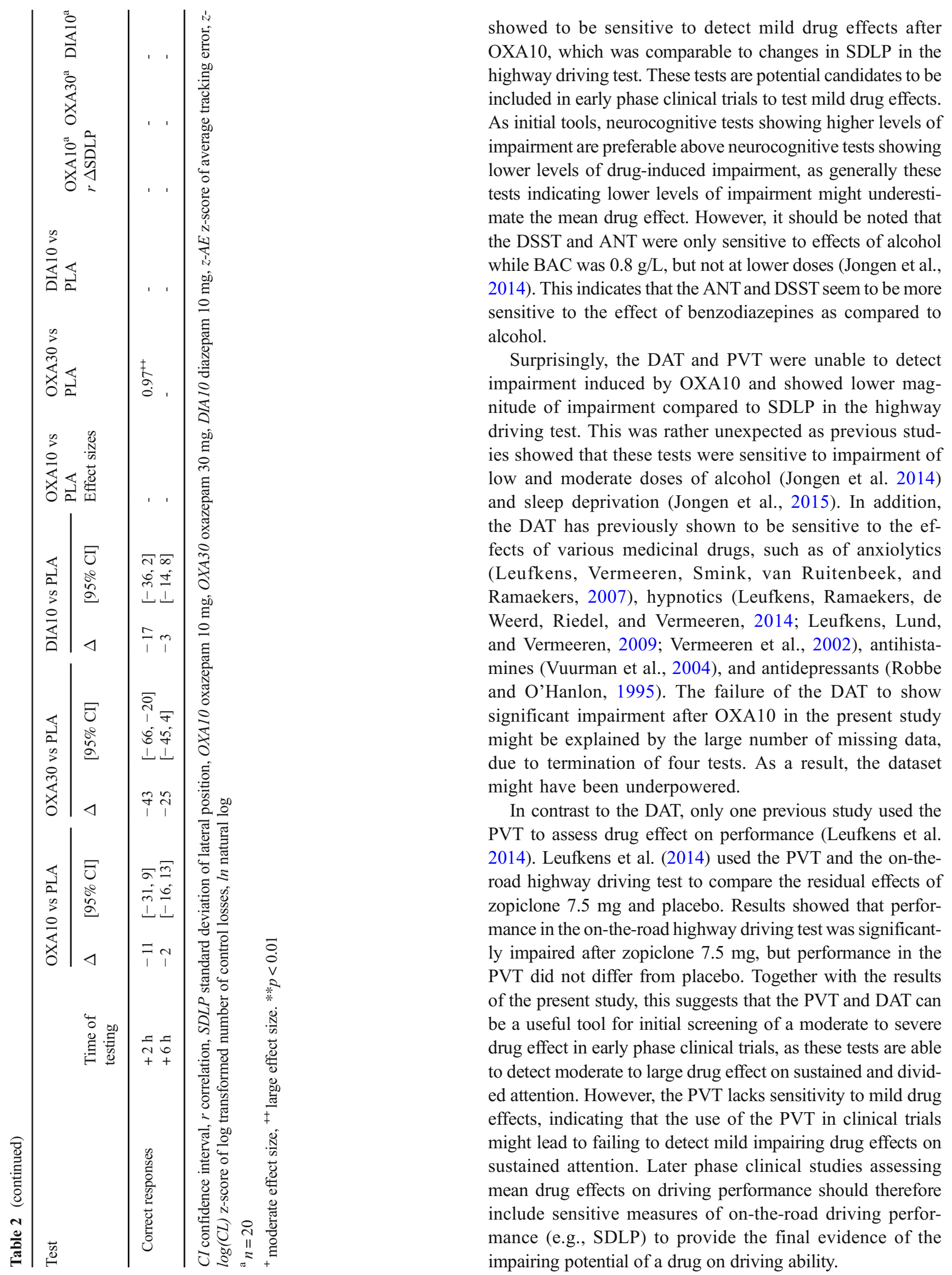

showed to be sensitive to detect mild drug effects after OXA10, which was comparable to changes in SDLP in the highway driving test. These tests are potential candidates to be included in early phase clinical trials to test mild drug effects. As initial tools, neurocognitive tests showing higher levels of impairment are preferable above neurocognitive tests showing lower levels of drug-induced impairment, as generally these tests indicating lower levels of impairment might underestimate the mean drug effect. However, it should be noted that the DSST and ANT were only sensitive to effects of alcohol while BAC was $0.8 \mathrm{~g} / \mathrm{L}$, but not at lower doses (Jongen et al., 2014). This indicates that the ANT and DSST seem to be more sensitive to the effect of benzodiazepines as compared to lcohol.

Surprisingly, the DAT and PVT were unable to detect mpairment induced by OXA10 and showed lower mages showed that these tests were sensitive to impairment of doses of alcohol (Jongen et al. 2014) fects of various medicinal drugs, such as of anxiolytics (Leufkens, Vermeeren, Smink, van Ruitenbeek, and Ramaekers, 2007), hypnotics (Leufkens, Ramaekers, de Weerd, Riedel, and Vermeeren, 2014; Leufkens, Lund, antihistaIn contrast to the DAT, only one previous study used the Th to assess drug effect on performance (Leufkens et al. PVT and the on-theeffects of piclone $7.5 \mathrm{mg}$ and placebo. Results showed that perfornce in the on-the-road highway driving test was significantimpaired after zopiclone $7.5 \mathrm{mg}$, but performance in the VT did not differ from placebo. Together with the results the present study, this suggests that the PVT and DAT can e a useful tool for initial screening of a moderate to severe rug effect in early phase clinical trials, as these tests are able detect moderate to large drug effect on sustained and dividd attention. However, the PVT lacks sensitivity to mild drug effects, indicating that the use of the PVT in clinical trials might lead to failing to detect mild impairing drug effects on sustained attention. Later phase clinical studies assessing mean drug effects on driving performance should therefore include sensitive measures of on-the-road driving perforimpairing potential of a drug on driving ability. 


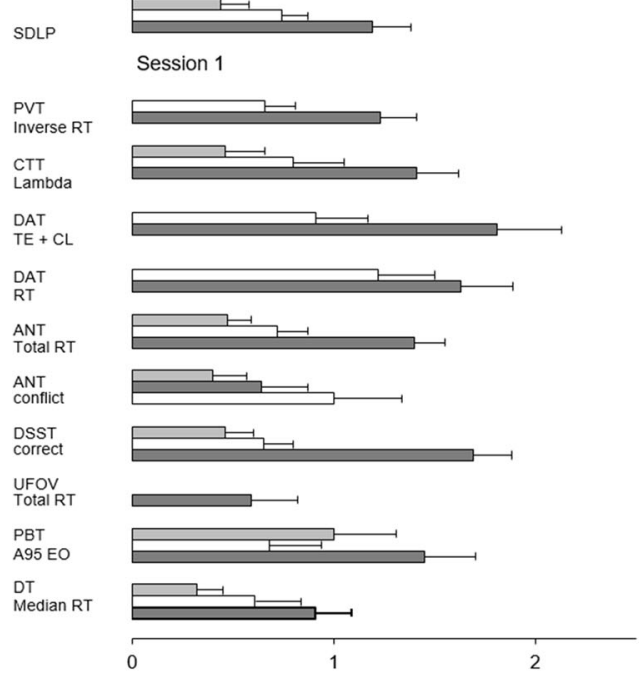

Fig. 3 Mean baseline-normalized significant $z$-scores of oxazepam $10 \mathrm{mg}$ (OXA10), diazepam $10 \mathrm{mg}$ (DIA10), and oxazepam $30 \mathrm{mg}$ (OXA30) compared with placebo across dependent variables of neurocognitive tests. SDLP in the highway driving tests is included as reference test. $\mathrm{PVT}=$ psychomotor vigilance test, $\mathrm{CTT}=$ critical tracking

The levels of drug-induced impairment found in these neurocognitive tests after intake of these prototypical sedative drugs can be used as thresholds of drug-induced impairment in future studies. A recent review indicated the lack of information regarding clinical relevance of neurocognitive impairment in medicated patient populations (van der Sluiszen et al., 2017). The present results can help to identify those patient groups who are at risk in traffic by, for example, comparing the benchmarks in neurocognitive tests after acute drug administration with long-term use of drugs in patient populations.

The present study found that only 4 out of 96 correlations between driving impairment and neurocognitive test performance were statistically significant. These correlations were a best moderately strong, and found in 3 out of 8 neurocognitive tests, i.e., the PVT, ANT, and PBT. No parameter consistently correlated (i.e., for all three treatment conditions) with driving impairment. In addition, no significant correlations were found between performance changes in the DAT, CTT, DSST, DT, and UFOV, showing that these tests are not associated with driving impairment as measured with changes in SDLP. The results of the present study are in line with previous reviews concluding that only some neurocogntive correlate moderately at best with actual driving impairment (Jongen et al. 2015; Ramaekers, 2003; Verster and Roth, 2012). Overall, neurocognitive tests clearly measure different aspects of drug-induced impairment as compared to SDLP. However, neurocognitive tests may have added value in assessing these drug effects in early phase clinical trials as these are easy to administer and cost-effective.
口OXA10 口DIA10 घOXA30

$$
\text { Session } 2
$$

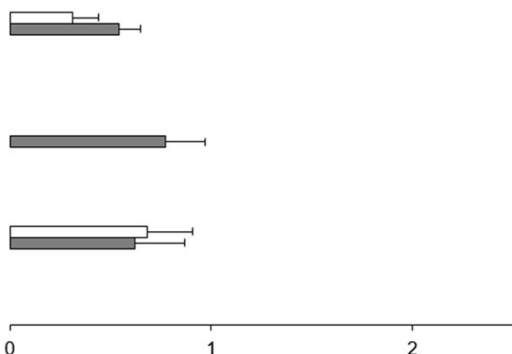

test, $\mathrm{DAT}=$ divided attention test, $\mathrm{ANT}=$ attention network test, $\mathrm{DSST}=$ digit symbol substitution test, UFOV $=$ useful field of view, $\mathrm{PBT}=$ postural balance test, $\mathrm{DT}=$ determination test, $\mathrm{RT}=$ reaction time, $\mathrm{TE}=$ tracking error, $\mathrm{CL}=$ control losses, $\mathrm{A} 95 \mathrm{EO}=$ area $95 \%$ eyes open. Error bars indicate the standard error of the mean

A limitation of the present study may be that neurocognitive tasks are compared with SDLP to assess drug-induced driving impairment. Although SDLP reflects road tracking control as a fundamental and realistic aspect of driving, it only measures highly automated performance at an operational level as part of driving performance (Michon, 1989). Driving performance also includes risk assessment, decision making and interaction with other road users. The predictive validity of the selected neurocognitive tests to measure drug-induced driving impairment could be underestimated as these tests might measure different relevant aspects of driving performance. Nevertheless, SDLP remains the most valid and sensitive measure to assess a drug's impairing potential on driving performance.

In conclusion, it was shown that single doses of OXA10 caused minor, DIA10 moderate, and OXA30 severe driving impairment. The DSST, ANT, PBT, and DT were able to detect mild effects of OXA10, but - except for the ANT - were not associated with driving impairment. These tests are potential candidate tests to measure mild drug effects in early phase clinical trials. However, no neurocognitive test is able to replace the on-the-road highway driving test.

Acknowledgments The authors would like to thank Anita van Oers, Eline Haijen, Ellen Houben, Shamyra Coleman, Jorn Jongen, and Caroline Steins for their assistance in data collection, Cees van Leeuwen MD, for the medical supervision, Henk Brauers and Hans Sleebe for ensuring the safety of the participants during the highway driving test, and Irma Brauers for the logistic work.

\section{Compliance with ethical standards}


The study was conducted in accordance with the code of ethics on human experimentation established by the declaration of Helsinki (1964) and amended in Seoul (2008). All participants were informed about the study's goal, procedures, and potential hazards in writing, and they gave their informed consent in writing. The Medical Ethics Committees of Maastricht University approved the study. Participants received a financial compensation for their participation in the study.

Open Access This article is distributed under the terms of the Creative Commons Attribution 4.0 International License (http:// creativecommons.org/licenses/by/4.0/), which permits unrestricted use, distribution, and reproduction in any medium, provided you give appropriate credit to the original author(s) and the source, provide a link to the Creative Commons license, and indicate if changes were made.

\section{References}

Alvarez F, del Río M (2002) Medicinal drugs and driving: from research to clinical practice. Trends Pharmacol Sci 23(9):441-443

Basner M, Dinges DF (2011) Maximizing sensitivity of the psychomotor vigilance test (PVT) to sleep loss. Sleep 34(5):581-591

Berghaus, G., \& Friedel, B. (1999). Guidelines on experimental studies undertaken to determine a medicinal drug's effect on driving or skills related to driving. Report of ICADTS Working Group

Bezemer KD, Smink BE, van Maanen R, Verschraagen M, de Gier JJ (2014) Prevalence of medicinal drugs in suspected impaired drivers and a comparison with the use in the general Dutch population. Forensic Sci Int 241:203-211

Borkenstein R, Crowther RF, Shumate RP, Zeil WW, Zylinan R (1964) The role of the drinking in traffic accidents. Department of Police Administration, Indiana University, Bloomington, IN

Boyle J, Danjou P, Alexander R, Calder N, Gargano C, Agrawal N, Murphy, G M (2009) Tolerability, pharmacokinetics and nighttime effects on postural sway and critical flicker fusion of gaboxadol and zolpidem in elderly subjects. Br J Clin Pharmacol 67(2):180 190. https://doi.org/10.1111/j.1365-2125.2008.03331.x

Dassanayake T, Michie P, Carter G, Jones A (2011) Effects of benzodiazepines, antidepressants and opioids on driving: a systematic review and meta-analysis of epidemiological and experimental evidence. Drug Saf 34(2):125-156. https://doi.org/10.2165/ 11539050-000000000-00000

Dinges DF, Powell JW (1985) Microcomputer analyses of performance on a portable, simple visual RT task during sustained operations. Behav Res Methods Instrum Comput 17(6):652-655

Dry MJ, Burns NR, Nettelbeck T, Farquharson AL, White JM (2012) Dose-related effects of alcohol on cognitive functioning. PLoS One 7(11):e50977. https://doi.org/10.1371/journal.pone.0050977

Dunlap WP, Cortina JM, Vaslow JB, Burke MJ (1996) Meta-analysis of experiments with matched groups or repeated measures designs. Psychol Methods 1(2):170-177. https://doi.org/10.1037/1082989X.1.2.170

Edwards JD, Vance DE, Wadley VG, Cissell GM, Roenker DL, Ball KK (2005) Reliability and validity of useful field of view test scores as administered by personal computer. J Clin Exp Neuropsychol 27(5): 529-543. https://doi.org/10.1080/13803390490515432

Fan J, McCandliss BD, Sommer T, Raz A, Posner MI (2002) Testing the efficiency and independence of attentional networks. J Cogn Neurosci 14(3):340-347. https://doi.org/10.1162/ 089892902317361886

FDA Guidance for Industry: Evaluating Drug Effects on the Ability to Operate a Motor Vehicle Guidance forIndustry (Draft Guidance) (January 2015), available at: http://www.fda.gov/Drugs/
GuidanceComplianceRegulatoryInformation/Guidances/ UCM430374

Horne JA, Ostberg O (1976) A self-assessment questionnaire to determine morningness-eveningness in human circadian rhythms. Int $\mathrm{J}$ Chronobiol 4(2):97-110 Retrieved from http://www.ncbi.nlm.nih. gov/pubmed/1027738

International Council on Alcohol Drugs and Traffic Safety (ICADTS) (1999) Guidelines on studies undertaken to determine a medicinal drug's effect on driving or skills related to driving. Bundes Anstalt fuer Strassenwesen (BASt), Cologne, pp 1-13

Jex, H. R., McDonnell, J. D., \& Phatak, A. V. (1966). A “critical” tracking task for man-machine research related to the operator's effective delay time. I. Theory and experiments with a first-order divergent controlled element. NASA CR-616. NASA Contractor Report. NASA CR. United States. National Aeronautics and Space Administration, 1-105

Jongen S, Vuurman E, Ramaekers J, Vermeeren A (2014) Alcohol calibration of tests measuring skills related to car driving. Psychopharmacology 231(12):2435-2447. https://doi.org/10.1007/ s00213-013-3408-y

Jongen S, Perrier J, Vuurman EF, Ramaekers JG, Vermeeren A (2015) Sensitivity and validity of psychometric tests for assessing driving impairment: effects of sleep deprivation. PLoS One 10(2): e0117045. https://doi.org/10.1371/journal.pone.0117045

Kay, G. G., \& Logan, B. K. (2011). Drugged driving expert panel report: a consensus protocol for assessing the potential of drugs to impair driving (no. HS-811 438)

Kleykamp BA, Griffiths RR, Mintzer MZ (2010) Dose effects of triazolam and alcohol on cognitive performance in healthy volunteers. Exp Clin Psychopharmacol 18(1):1-16. https://doi.org/10. 1037/a0018407

Lakens D (2013) Calculating and reporting effect sizes to facilitate cumulative science: a practical primer for t-tests and ANOVAs. Front Psychol 4(863). https://doi.org/10.3389/fpsyg.2013.00863

Leufkens TRM, Vermeeren A (2014) Zopiclone's residual effects on actual driving performance in a standardized test: a pooled analysis of age and sex effects in 4 placebo-controlled studies. Clin Ther 36(1):141-150. https://doi.org/10.1016/j.clinthera.2013.11.005

Leufkens TRM, Vermeeren A, Smink BE, van Ruitenbeek P, Ramaekers JG (2007) Cognitive, psychomotor and actual driving performance in healthy volunteers after immediate and extended release formulations of alprazolam $1 \mathrm{mg}$. Psychopharmacology 191(4):951-959. https://doi.org/10.1007/s00213-006-0669-8

Leufkens TRM, Lund JS, Vermeeren A (2009) Highway driving performance and cognitive functioning the morning after bedtime and middle-of-the-night use of gaboxadol, zopiclone and zolpidem. J Sleep Res 18(4):387-396. https://doi.org/10.1111/j.1365-2869. 2009.00746.x

Leufkens TRM, Ramaekers JG, de Weerd AW, Riedel WJ, Vermeeren A (2014) Residual effects of zopiclone $7.5 \mathrm{mg}$ on highway driving performance in insomnia patients and healthy controls: a placebo controlled crossover study. Psychopharmacology 231(14):27852798. https://doi.org/10.1007/s00213-014-3447-z

Louwerens J, Gloerich A, de Vries G, Brookhuis K, O’Hanlon J (1987) The relationship between drivers' blood alcohol concentration (BAC) and actual driving performance during high speed travel. In: Noordzij PC, Roszbach R (eds) Alcohol drugs traffic safety. T86 Elsevier, Amsterdam, pp 183-186

McLeod DR, Griffiths RR, Bigelow GE, Yingling J (1982) An automated version of the digit symbol substitution test (DSST). Behav Res Methods Instrum 14(5):463-466. https://doi.org/10.3758/ BF03203313

Michon JA (1989) Explanatory pitfalls and rule-based driver models. Accid Anal Prev 21(4):341-353

Moskowitz, H. (1973). Laboratory studies of the effects of alcohol on some variables related to driving. Journal of Safety Research 
Mulder-Hajonides van der Meulen WREH, Wijnberg JR, Hollander JJ, De Diana IPF, Van den Hoofdakker RH (1981) Measurement of subjective sleep quality. In Proceedings of the International European Sleep Congress. Elsevier, Amsterdam

Neutel CI (1995) Risk of traffic accident injury after a prescription for a benzodiazepine. Ann Epidemiol 5(3):239-244

O'Hanlon JF (1984) Driving performance under the influence of drugs: rationale for, and application of, a new test. $\mathrm{Br} \mathrm{J}$ Clin Pharmacol 18(Suppl 1):121S-129S

O'Hanlon JF, Ramaekers JG (1995) Antihistamine effects on actual driving performance in a standard test: a summary of Dutch experience, 1989-94. Allergy 50(3):234-242

O’Hanlon JF, Haak TW, Blaauw GJ, Riemersma JB (1982) Diazepam impairs lateral position control in highway driving. Science 217(4554):79-81

O'Hanlon JF, Brookhuis KA, Louwerens JW, Volkerts ER (1986) Performance testing as part of drug registration. Drugs Driving: 311-320

Owens, K., \& Ramaekers, J. G. (2009). Drugs, driving, and models to measure driving impairment. In Drugs, driving and traffic safety (pp. 43-58). Birkhäuser Basel

Ramaekers JG (2003) Antidepressants and driver impairment: empirical evidence from a standard on-the-road test. J Clin Psychiatry 64(1): 20-29

Ray WA, Fought RL, Decker MD (1992) Psychoactive drugs and the risk of injurious motor vehicle crashes in elderly drivers. Am J Epidemiol 136(7):873-883

Robbe HW, O'Hanlon JF (1995) Acute and subchronic effects of paroxetine 20 and $40 \mathrm{mg}$ on actual driving, psychomotor performance and subjective assessments in healthy volunteers. Eur Neuropsychopharmacol 5(1):35-42

Roth T, Eklov SD, Drake CL, Verster JC (2014) Meta-analysis of on-theroad experimental studies of hypnotics: effects of time after intake, dose, and half-life. Traffic Inj Prev 15(5):439-445. https://doi.org/ $10.1080 / 15389588.2013 .830211$

Schuhfried G (2005) Manual expert system traffic (XPSV). SCHUHFRIED GmbH, Mödling
Seppala T, Linnoila M, Mattila MJ (1979) Drugs, alcohol and driving. Drugs 17(5):389-408

van der Sluiszen NNJJM, Vermeeren A, Jongen S, Vinckenbosch F, Ramaekers JG (2017) Influence of long-term benzodiazepine use on neurocognitive skills related to driving performance in patient populations: a review. Pharmacopsychiatry. https://doi.org/10. 1055/s-0043-112755

Tiplady B, Hiroz J, Holmes L, Drummond G (2003) Errors in performance testing: a comparison of ethanol and temazepam. $\mathrm{J}$ Psychopharmacol 17(1):41-49. https://doi.org/10.1177/ 0269881103017001691

Vermeeren A (2004) Residual effects of hypnotics: epidemiology and clinical implications. CNS Drugs 18(5):297-328

Vermeeren A, Gier JJ, O'Hanlon JF (1993) Methodological guidelines for experimental research on medicinal drugs affecting driving performance: an international expert survey. University of Limburg, Institute for Human Psychopharmacology

Vermeeren A, Riedel WJ, van Boxtel MPJ, Darwish M, Paty I, Patat A (2002) Differential residual effects of zaleplon and zopiclone on actual driving: a comparison with a low dose of alcohol. Sleep 25(2):224-231

Verster JC, Roth T (2011) Standard operation procedures for conducting the on-the-road driving test, and measurement of the standard deviation of lateral position (SDLP). Int J Gen Med 4:359-371. https:// doi.org/10.2147/IJGM.S19639

Verster JC, Roth T (2012) Predicting psychopharmacological drug effects on actual driving performance (SDLP) from psychometric tests measuring driving-related skills. Psychopharmacology 220(2):293-301. https://doi.org/10.1007/s00213-011-2484-0

Vuurman EFPM, Rikken GH, Muntjewerff ND, de Halleux F, Ramaekers JG (2004) Effects of desloratadine, diphenhydramine, and placebo on driving performance and psychomotor performance measurements. Eur J Clin Pharmacol 60(5):307-313. https://doi.org/10. 1007/s00228-004-0757-9

Walsh JM, Verstraete AG, Huestis, M. a, \& Mørland, J. (2008) Guidelines for research on drugged driving. Addiction 103(8):1258-1268. https://doi.org/10.1111/j.1360-0443.2008.02277 